Research report

\title{
Ingredients of gender-based stereotypes about food. Indirect influence of food type, portion size and presentation on gendered intentions to eat
}

\author{
Nicoletta Cavazza a,*, Margherita Guidetti a, Fabrizio Butera ${ }^{\text {b }}$ \\ a Università di Modena e Reggio Emilia, Italy \\ ${ }^{\mathrm{b}}$ University of Lausanne, Switzerland
}

\section{A R T I C L E I N F O}

\section{Article history:}

Received 5 October 2014

Received in revised form 25 March 2015

Accepted 24 April 2015

Available online 28 April 2015

\section{Keywords:}

Gender-based stereotype about food

Portion size

Dish presentation

\begin{abstract}
A B S T R A C T
The association between certain foods and masculinity or femininity has been widely discussed in different disciplines. However, extant research has yet to clarify which are the critical dimensions lending these gender connotations to food and thus impacting on the willingness to eat it. We present a study on the role of food type, portion size, and dish presentation as potential factors constituting the genderbased stereotype about food, and their indirect or mediated effect on the intention of men and women to eat certain feminine/masculine stereotyped foods. We manipulated the three features cited above in a 2 (food type: Caprese vs. hamburger) $\times 2$ (portion size: small vs. big) $\times 2$ (presentation: elegant vs. rough) full factorial design. Results confirmed a model of moderated mediation: the Caprese salad, the small portion and the elegantly presented dish (in respect to the hamburger, the big portion and the roughly presented dish) tend to be considered "feminine food", and thus women expressed a more pronounced intention to eat it than men. The implications of the findings for both theory and practice are discussed.

(C) 2015 Published by Elsevier Ltd.
\end{abstract}

\section{Introduction}

Meat (preferably roasted and in large portions) is food for men, while a little mixed salad is food for women. This is the extreme synthesis of the widespread gender-based stereotype about food. Anthropologists have shown that associations between food and masculinity/femininity are present in every human culture, although with some specific variations (e.g. Counihan \& Kaplan, 2004). Psychologists have also long studied the nature (e.g., food type and their nutritional features, portion size) and the implications of foodgender associations in terms of food choice, social judgment and impression management (O’Doherty Jensen \& Holm, 1999; Vartanian, Herman, \& Polivy, 2007). However, the analysis of the extant knowledge in this domain does not allow clear identification of the "ingredients" of such a gender-based stereotype about food.

Indeed, food type, nutritional features (e.g. fat content, healthiness) and meal size often covary in differentiating masculine and feminine lay categories of foods. This has prevented previous research from disentangling the contribution of the different dimensions in defining the gender connotation of food and their behavioral impact. In addition, little is known about the gendered effect of a now often cared aspect of food consumption: its plating,

\footnotetext{
* Corresponding author.

E-mail address: nicoletta.cavazza@unimore.it (N. Cavazza).
}

i.e., the food arrangement in the dish. Since neatness and elegance, as opposed to roughness, are dimensions included in the lay conceptions of masculinity and femininity (Helgeson, 1994), it is important to explore the role that the aesthetic meal presentation may play in the process of building the gender based stereotypes about food and their influence on people's choices. In sum, what makes a food a masculine/feminine food? Its nature (e.g. being meat or vegetables), its size and its neatness, or a complex set of these features? And which of them affects the food choice of women and men? We devised the present experiment to answer these questions.

\section{Gender-based stereotypes about food}

According to the review of Vartanian et al. (2007), foods conveying masculine or feminine character differ mainly across two dimensions: type and quantity. As regards food type, many studies converge on a consistent result: Red meat is the quintessential masculine food (Fiddes, 1991). The fact that meat is a symbolic marker of masculinity may be due first of all to the aggressive, virile and powerful actions needed for its supply and processing (Lupton, 1996). Indeed, butchers are almost exclusively men, and female butchers are a cultural category even difficult to imagine (Pringle \& Collings, 1993). Second, meat as a food is commonly associated to concepts such as strength, virility, (patriarchal) tradition (O'Doherty Jensen \& Holm, 1999; Rozin, Hormes, Faith, \& Wansink, 2012), to the extent that it has been shown that a primary reason for men to eat meat 
is just to feel like real men (Rothgerber, 2013). Conversely, vegetables, dairy products, fish, fruit and sweets are generally considered feminine foods (O'Doherty Jensen \& Holm, 1999), even though femininity is rather associated with what women do not eat, for example with eating lightly or dieting (Bourdieu, 1984; Fagerli \& Wandel, 1999; Sobal, 2005). Empirical evidence confirmed that these genderbased stereotypes about food are largely shared by men and women (Kimura et al., 2009, 2012; Rozin et al., 2012).

The food-gender associations at the basis of the gendered consumption stereotype were most often inferred from the judgment of masculinity or femininity about a target eating certain foods (e.g., Stein \& Nemeroff, 1995). The only exception, to the best of our knowledge, in which the food-gender associations emerged directly both at the explicit and implicit level was the study of Kimura et al. (2009). This study, carried out in Japan, also proved that the content of the gender-based stereotypes about food is for the most part not specific of Western cultures: In this experiment four out of six courses associated to men contained meat, whereas none of the six associated to women included it.

As far as quantity is concerned, some studies showed that eating little elicits a feminine impression (Chaiken \& Pliner, 1987; Pliner \& Chaiken, 1990); however in many cases meal size and amount of calories covary with food type (e.g. Kimura et al., 2009). This may be due to the fact that meal size and food type are indeed strictly connected in real meals (Martins, Pliner, \& Lee, 2004). However, Vartanian et al. (2007) cited in their review an unpublished study by Vartanian in which the two dimensions were manipulated separately and the meal size manipulation impacted more than the meal type social judgment of femininity/masculinity. Aside from this unpublished study, we did not find any other empirical evidence of the potential disjointed effects of portion size and food type on the food-gender association.

\section{Effects of gender-based stereotypes about food}

Food choice often serves impression management and identity signaling goals. This is true, in particular, when people eat with observers or other co-eaters they believe are evaluating them (e.g. supervisors or dating partners; for a review see Herman, Roth, \& Polivy, 2003). More to the point, the consumption of genderstereotyped foods or meals may be a means to convey a masculine or feminine identity (Sobal, 2005). A great deal of research has been devoted to study the impression that an eater induces to observers or co-eaters as a function of her/his stereotypical congruent or incongruent food choice (for a review see Vartanian et al., 2007). Globally, this line of research confirmed that both men and women eating "feminine" foods are indeed rated as more feminine than people eating "masculine" foods (Chaiken \& Pliner, 1987; Mooney \& Lorenz, 1997; Mori, Chaiken, \& Pliner, 1987; Stein \& Nemeroff, 1995).

Furthermore, these gender-based stereotypes about food exert an impact on food-related practices and preferences: Through socialization individuals learn a masculine or feminine eating style (Rolls, Fedoroff, \& Guthrie, 1991), so that they tend to prefer and eat gender-congruent food and to avoid food associated with a dissociative reference group (e.g., women for men, White \& Dahl, 2006) because this is an appropriate behavior with their sex role (for a review, O’Doherty Jensen \& Holm, 1999). In line with this socialization explanation, Mori et al. (1987), for example, showed that female participants ate less when paired with an attractive opposite-sex experimental partner (Study 1) or under condition of threatened gender identity (Study 2). In addition, participants in Pliner and Chaiken's Study 2 (1990) reported that they would eat less in order to appear feminine and would eat more in order to appear masculine. These results confirm that eating behaviors are also motivated by the need to convey and strengthen a congruent gender identity.

Recently, Gal and Wilkie (2010) studied the effect of food masculinity or femininity on food choice, irrespective of particular impression management motivations. They placed their experimental participants in conditions of high vs. low cognitive resources availability and asked them to order a meal from a menu in which the same courses were named in a feminine or in a masculine way. They observed that, whereas men chose less feminine items in condition of high (vs. low) resources availability, women always tended to choose more feminine than masculine items, irrespective of resources availability. The authors interpreted this difference as evidence of a heavier gender-role normative pressure on men than on women. On the contrary, in our interpretation, it might indicate that women have interiorized the genderrole normative pressure to such an extent that congruent behaviors arise automatically even when cognitive resources are lowered. Indeed, in contrast with Gal and Wilkie's (2010) interpretation, previous studies showed that the social effects on food intake are especially strong in women. For example, the manipulation of the portion size eaten by a target affected more the impressions about women than those about men (Chaiken \& Pliner, 1987), and women were observed to lower their calories consumption when eating with a man (vs. another woman), whereas men did not vary their eating behavior as a function of the co-eater's gender (Young, Mizzau, Mai, Sirisegaram, \& Wilson, 2009). Thus Vartanian et al. (2007, p. 273) concluded that: "perhaps eating a particular amount is not a tactic available to men for bolstering their masculine image." Since implicit norms, like those concerning gender-role appropriate behaviors, may be specific to social environments or groups, they probably exert different pressures on men and women in different contexts. Therefore, whether the social pressures deriving from gender-based stereotypes about food are more binding for men than for women cannot be answered in an uncontroversial way.

To summarize, the findings of Gal and Wilkie (2010) and those of Pliner and Chaiken (1990, Study 2) suggest that people are somewhat aware of the potential use of food choice as a tool of impression management. Moreover, Gal and Wilkie's (2010) study, manipulating the course description while keeping its content constant, poses a new question as to whether, beyond meal type and size, gender-based stereotypes about food also concern dish presentation. Evidence of the role of this visual cue on gender connotation of food, although plausible, is very scant.

\section{The effect of dish presentation}

Many chefs and cooking amateurs pay much attention to the arrangement of the food in the dish. Undoubtedly, this is a trend of the moment, but they also may know that the aesthetic appeal of the course induces expectations about food taste and palatability, and finally influences the desire to eat that food (for a review, see Wadhera \& Capaldi-Phillips, 2014). However, empirical evidence of the effect exerted by different visual cues related to food on liking and eating is still modest. A line of research concerned, for example, the neatness of presentation, showing that a food in a neat plating was liked more than the same food presented in a messy way (Zellner et al., 2011). In addition, a neat and creative presentation induced a better food evaluation than a neat and traditional one (Zellner, Loss, Zearfoss, \& Remolina, 2014).

To the best of our knowledge, only Kimura et al. (2012) focused their attention on presentation cues potentially able to affect genderbased stereotypes about food. They explored, through a semantic priming task, the combined effect of the gendered connotations of the dish and the food contained in it on the implicit foodgender associations. They arranged feminine (salad or pasta) or 
masculine (two meat preparations) foods either in a perceived feminine or masculine dish (as resulting from a pilot study), in order to have congruent or incongruent food-dish combinations. The results showed that the congruent conditions facilitated the semantic association of the food-dish combinations with gender, thus confirming that gender connotations of dishes also contributed to the gender stereotypes about food. This suggests that the genderbased stereotypes concerning a certain food may actually originate not only from its type (e.g., being meat) or its heaviness (e.g., portion size or calories amount) but also from its appearance.

A so far unexplored and gender-pertinent dimension of food appearance could be the elegance (vs. roughness) of plating. Indeed, elegance and roughness are included respectively in the lay conceptions of femininity and masculinity (Helgeson, 1994). Hence, an elegant rather than a rough presentation may facilitate the activation of a feminine rather than masculine stereotype, just as in the study by Kimura et al. (2012). Exploring the role of elegant/rough presentation, along with that of food type and portion size, in substantiating the gender-based stereotypes about food was the first goal of our study.

\section{The present experiment}

The purpose of this study was twofold. On the one hand, we wanted to test the independent, additive or interactive impact of the different dimensions - i.e., food type, portion size, and dish presentation - potentially constituting the gender-based stereotype about food. Such a test would contribute to the literature on gendered stereotypes about food in two significant ways: it would allow (a) to disentangle the often confounded effects of meal size and meal type on the stereotype, and (b) to determine whether elegance of presentation may be another significant aspect feeding this same stereotype. On the other hand, despite the empirical evidence concerning food choice as a gendered impression management tool, to the best of our knowledge, the effect of foodgender associations on individuals' food choice has not been examined directly, irrespective of impression management motivations. Thus, we wanted to study whether the three dimensions considered would influence the intention of men and women to eat certain foods because they are stereotypically perceived as feminine/masculine.

To this end, we carried out an experimental study in which we manipulated the three features cited above (meal type, portion size and presentation) in order to test their impact on the foodgender associations (stereotype) and on the intention to eat expressed by male and female participants. Building on the literature discussed above, we expected that:

Hypothesis 1: A Caprese salad (mozzarella and tomatoes), an elegantly presented course, and a small portion should independently and additively elicit a higher feminine connotation in comparison to a hamburger, a rough presentation and a big portion.

Hypothesis 2: Food type, course presentation and portion size should affect intention to eat the proposed food through food-gender associations moderated by respondents' gender. Hence, we will test a model of moderated mediation. As previous research found that the food-gender associations are held by both women and men (Kimura et al., 2009, 2012; Rozin et al., 2012) we do not expect gender to moderate the path from the independent variables to the mediator. However, we hypothesize that gender moderates the mediator-dependent variable link, i.e., women's intention to eat a dish should be a positive function, whereas men's intention should be a negative function, of the perceived femininity (vs. masculinity) of that dish.

\section{Method}

\section{Participants}

Two hundred and eight participants (54.8\% women) aged 17$57(M=25.38, S D=4.73)$ were recruited through personal mailing list, Facebook contacts and snowball sampling. They gave their informed consent to participate in the study and were asked to complete an online questionnaire about food habits implemented on the LimeSurvey platform.

\section{Design and procedure}

Participants were randomly assigned to conditions in a 2 (type of food: hamburger vs. Caprese salad) $\times 2$ (portion size: large vs. small $) \times 2$ (presentation: rough vs. elegant) full factorial design. In a pilot study we asked 20 participants to categorize a list of 26 prepared dishes according to how much they associated these dishes to men, women, both of them, none of them. From the results, we selected the two dishes most generally associated to men (hamburger, 65\%) and to women (Caprese, 65\%). Then we prepared eight photos of the courses operationalizing our independent variables. ${ }^{1}$ In the large portion size condition we arranged in a white dish, either in an elegant or in a rough way, a 250-grams minced-beef patty accompanied by $100 \mathrm{~g}$ of lettuce and tomato dressed with $10 \mathrm{~g}$ of olive oil and $10 \mathrm{~g}$ of mayonnaise (for a total of 554 calories) vs. $200 \mathrm{~g}$ of mozzarella cheese accompanied with $100 \mathrm{~g}$ of tomato dressed with $10 \mathrm{~g}$ of olive oil (for a total of 550 calories). In the small portion condition, half of the same ingredients were used to form the two courses, disposed either in an elegant or in a rough way. Participants first reported their usual frequency of meat and vegetables consumption, then they were presented the picture of the hamburger or Caprese followed by the questions relative to the manipulation checks (perception of roughness, portion size, healthiness, and calories estimation) and the dependent variables (see below).

\section{Measures}

\section{Gender based stereotype about food}

A score of association between masculine/feminine and portrayed dish was computed based on three items: a 10-point bipolar item anchored to masculine $(=1)$ and feminine $(=10)$ and two 10 point items asking the degree of appropriateness of the observed dish for men and for women. First, a total score of appropriateness was calculated subtracting the appropriateness of the dish for men from the appropriateness of the dish for women. After recoding the resulting score, as well as the bipolar score, on a 0-10 scale, we averaged them to obtain an index of masculine/feminine association with the food (items correlation $=.48$ ). Higher scores correspond to feminine association $(M=6.18, S D=2.03)$.

\section{Intention to eat}

An index of behavioral intention was computed $(\alpha=.84)$ as the mean of four items (e.g. I would order this course in a dinner with friends). The answers were given on a 10 -point scale (from 1 = very unlikely to 10 = very likely; $M=4.57, S D=2.25$ ).

\section{Meat and vegetables consumption frequency}

Participants were asked to report how often, in the 14 weekly meals, they usually eat meat $(M=6.13, S D=3.19)$ and vegetables

\footnotetext{
1 The images employed can be found in the online supplementary materials.
} 
$(M=7.72, S D=3.91$; range: $0-14)$. These frequencies were included as covariates in the analyses concerning intention to eat.

\section{Manipulation checks}

Perceived roughness and perceived portion size served as manipulation checks. They were assessed by two bipolar 10-point items anchored to either elegant or small $(=1)$ and either rough or big $(=10)$. In addition, as Chernev and Gal (2010) found that putting a salad aside from a hamburger significantly decreased the calories estimation in respect to the hamburger alone, we also checked for the perception of healthiness and calories estimation through two items, whose answer ranged from very low $(=1)$ to very high $(=10)$.

\section{Results}

\section{Manipulation checks}

The analysis of variance including type of food (hamburger vs. Caprese), the manipulation of presentation (elegant vs. rough), and portion size (big vs. small) performed on the perceived roughness confirmed that the exposed dishes were evaluated as rougher in the rough condition $(M=5.16, S D=2.21)$ than in the elegant condition $(M=4.10, S D=2.25), F(1,197)=12.35, p<.001, \eta_{\mathrm{p}}{ }^{2}=.06$. The main effect of food type also emerged, $F(1,197)=4.89, p=.03, \eta_{\mathrm{p}}{ }^{2}=.02$, showing that globally the hamburger was perceived always as rougher than the Caprese. On the contrary, the variation in the portion size did not affect the roughness evaluation.

The same analysis performed on the perceived portion size confirmed that the dishes were indeed evaluated as larger in the large condition $(M=4.71, S D=1.82)$ than in the small condition $(M=3.05$, $S D=2.23), F(1,198)=26.84, p<.001, \eta_{\mathrm{p}}{ }^{2}=.12$; the differences in degrees of freedom are due to missing values. The significant interaction between portion size and presentation, $F(1,198)=4.21$, $p=.04, \eta_{\mathrm{p}}{ }^{2}=.02$, signaled that the difference between portions was perceived as greater when participants were presented the elegant dish rather than the rough one.

Finally, even though the two courses were arranged to be comparable in terms of calories and healthiness, we found that, despite the presence of lettuce and tomato aside from the hamburger, our participants perceived the hamburger as less healthy $(M=5.91$, $S D=2.33)$ and more caloric $(M=4.73, S D=2.33)$ than the Caprese $\left(M_{\text {healthy }}=7.72, S D=3.05 ; M_{\text {caloric }}=3.44, S D=3.47\right), F_{\text {healthy }}(1,204)=23.37$, $p<.001 ; F_{\text {caloric }}(1,205)=14.99, p<.001$.

\section{Preliminary analyses}

Before our focal analyses, we checked whether men and women in our sample reported different habits of consumption regarding the two main food categories: meat and vegetables. Consistent with prior research (e.g., Rothgerber, 2013), men reported to eat meat an average of $6.63(S D=3.05)$ times a week, whereas for women the mean frequency was $5.74(S D=3.29), F(1,203)=3.94, p=.05$, $\eta_{\mathrm{p}}{ }^{2}=.02$. On the contrary, women reported to eat vegetable more frequently $(M=8.29, S D=3.85)$ than men $(M=7.01, S D=3.91), F(1$, $203)=5.53, p=.02, \eta_{\mathrm{p}}{ }^{2}=.03$. Due to these baseline differences, and in order to detect the moderating effect of respondents' gender net of food habits, we included the frequency of meat and vegetables consumption as covariates in all the subsequent analyses.

\section{Dimensions of gendered stereotypes}

A first 2 (type of food) $\times 2$ (portion size) $\times 2$ (presentation) between-participants ANCOVA design was performed on the masculinity/femininity association. Table 1 shows means and standard deviations for each experimental condition. The analysis yielded a main effect of type of food, $F(1,196)=15.83, p<.001, \eta_{\mathrm{p}}^{2}=.07$;
Table 1

Means and standard deviation (in parentheses) of femininity/masculinity association of dishes as a function of type of food, portion size and presentation. Higher scores indicate more femininity.

\begin{tabular}{lllll}
\hline Dish presentation & Size & Caprese & Hamburger & Total \\
\hline Rough & Large & $6.33(1.84) \mathrm{a}$ & $4.31(1.68) \mathrm{a}$ & $5.23(2.01)$ \\
& Small & $6.61(1.80) \mathrm{a}$ & $5.72(1.46) \mathrm{b}$ & $5.15(1.68)$ \\
Elegant & Large & $6.26(1.65) \mathrm{a}$ & $4.48(1.96) \mathrm{a}$ & $5.47(2.02)$ \\
& Small & $6.89(1.39) \mathrm{a}$ & $7.71(1.69) \mathrm{c}$ & $7.45(1.63)$ \\
Total & & $6.51(1.67)$ & $5.90(2.24)$ & $6.18(2.03)$ \\
\hline
\end{tabular}

Note: Means with different letters in the same column differ from each other by at least $p<.05$.

a main effect of dish presentation, $F(1,196)=7.15, p=.008, \eta_{\mathrm{p}}{ }^{2}=.035$; as well as a main effect of portion size, $F(1,196)=30.88, p<.001$, $\eta_{\mathrm{p}}{ }^{2}=.14$. The interaction between portion size and presentation proved to be significant, $F(1,196)=4.50, p=.03, \eta_{\mathrm{p}}{ }^{2}=.02$, as well as the interaction between the type of food and the portion size, $F(1,196)=16.12, p<.001, \eta_{\mathrm{p}}{ }^{2}=.08$.

Globally, in line with the pre-test, the Caprese was perceived as more feminine than the hamburger ${ }^{2}$; in addition, a small portion appeared more feminine $(M=6.87, S D=1.77)$ than a large one $(M=5.33, S D=2.00)$; and an elegant presentation was evaluated as more feminine $(M=6.60, S D=2.05)$ than a rough one $(M=5.74$, $S D=1.91)$. The inspection of the simple effects showed that the Food $\times$ Portion size interaction was entirely due to the difference in the hamburger condition: The hamburger was perceived as most feminine when small, whereas it was perceived as most masculine when it was big, $F(1,107)=48.90, p<.001, \eta_{\mathrm{p}}{ }^{2}=.31$; on the contrary the femininity attributed to the Caprese did not change when portrayed in a large portion in comparison to a small portion, $F(1,87)=1.07 ; p=.30, \eta_{\mathrm{p}}{ }^{2}=.01$. The interaction between portion size and dish presentation showed that the dish presentation influenced the stereotype only when the portion size was small, $F(1$, $108)=13.54, p<.001, \eta_{\mathrm{p}}{ }^{2}=.11$, but not when it was big, $F(1,86)=.38$, $p=.85, \eta_{\mathrm{p}}{ }^{2}=.00$.

In synthesis, the Caprese was rated as a feminine food in all the conditions, whereas the hamburger, globally perceived as a less feminine food, lost its masculinity when accompanied with a feminine characteristic (i.e. small or elegantly presented). The same analysis including respondents' gender as a control variable revealed neither a significant main effect of this variable nor any interactions.

\section{Intention to eat}

As far as intention to eat is concerned, the 2 (food type) $\times 2$ (portion size) $\times 2$ (presentation) ANCOVA yielded the main effect of food type, $F(1,196)=4.15, p=.04, \eta_{\mathrm{p}}{ }^{2}=.02$, and that of portion size, $F(1,196)=12.11, p=.001, \eta_{\mathrm{p}}{ }^{2}=.06$. They indicated that participants were more willing to eat the Caprese than the hamburger, and they reported a greater intention to eat the food when it was a big portion than a small one (Table 2). The same analysis including respondents' gender as a control variable revealed neither a significant main effect of this variable nor any interactions.

\footnotetext{
2 The regression of the masculinity/femininity association entering type of food, portion size and presentation (dummies), perceived healthiness and caloric estimate as predictors shows that the effect of the type of food became non significant, $\beta=.01, p=.80$; whereas perceived healthiness, $\beta=.20, p=.001$, and caloric estimate, $\beta=-.41, p<.001$, remained significant. Thus, they fully mediated the effect of the type of food on the food-gender association, $R^{2}=.45, F(5,200)=32.68, p<.001$. Future research should also directly manipulate these food features in order to understand the causality direction: is a healthy and low calories food a feminine food, or rather is a feminine food perceived as healthy and low caloric as a consequence of the stereotype?
} 
Table 2

Means and standard deviation (in parentheses) of intention to eat the dish as a function of type of food, portion size and presentation.

\begin{tabular}{lllll}
\hline Dish presentation & Size & Caprese & Hamburger & Total \\
\hline Rough & Large & $5.31(2.05)$ & $5.08(2.07)$ & $5.19(2.04)$ \\
& Small & $4.80(2.44)$ & $3.82(1.81)$ & $4.36(2.22)$ \\
Elegant & Large & $5.58(2.17)$ & $4.78(2.53)$ & $5.21(2.36)$ \\
& Small & $4.17(2.04)$ & $3.62(2.02)$ & $3.80(2.12)$ \\
Total & & $4.99(2.23)$ & $4.22(2.21)$ & $4.56(2.25)$ \\
\hline
\end{tabular}

\section{Moderated mediation}

We carried out the analysis using PROCESS, the SPSS-macro provided by Hayes (2013). We tested model 14 entering meat and vegetables usual consumption as control variables and setting 5000 bootstrap resamples. Table 3 reports all the results, but for the sake of simplicity, and to avoid redundancy, we limited the discussion to the conditional indirect effect of type of food, portion size and dish presentation on the self-reported intention to eat the proposed food, through the food-gender association, moderated by the respondents' gender (Fig. 1).

The 95\% confidence intervals reported in the last rows of Table 3 indicated that a significant indirect effect on eating intention through the food-gender association by respondents' gender interaction emerged for food type, portion size and dish presentation. The inspection of this indirect effect indicated that, first, women reported a higher intention, while men reported a lower intention to eat the Caprese salad than the hamburger, at least in part as they perceived the former more feminine than the latter. Second, women were found more willing to eat a small rather than a large portion and an elegant rather than a rough course because they associated them with femininity, whereas no significant differences emerged for men. Thus, results confirmed that all of our manipulated variables indirectly affected women's intention to eat a food, through the food-gender associations. Globally, since a total effect of type of food and portion size on intention to eat was observed (see the ANCOVA above), the food-gender association played a role of (partial) mediator, whereas the effect of presentation on intention was only indirectly conveyed by food-gender association moderated by participants' gender.

\section{Discussion}

The association between certain foods and masculinity or femininity has been widely discussed by scholars in different disciplines. However, extant research has yet to clarify which are the critical dimensions lending these gender connotations to food. A first obstacle is that studies have often manipulated together food type and portion size. Moreover, they did not assess directly the eaters' perceived food-gender association and its impact on their intention to eat, particularly when no specific impression management motivation is activated. Our experiment moved from this line of research in order to fill these gaps. Moreover, we wanted to investigate an unexplored potential dimension of the gender-based stereotype about food, i.e., course presentation.

The results of our experiment confirmed our hypothesis 1, that food type, portion size, and course presentation influence the perceived association between food and gender. Indeed, we observed the most feminine evaluation when participants were exposed to the image of a small and elegant Caprese salad, and the most masculine evaluation when they watched the image of a big and rough hamburger. However, contrary to what was expected, their effects were not additive, as we also observed interactive effects between portion size and presentation and between portion size and type of food. This was an unexpected, but interesting result, because it signals that a single feminine connoted dimension (a feminine food, or an elegant presentation, or a small portion) was enough to increase the perception of a dish as feminine and to enhance women's willingness to eat it. Conversely, a single masculine feature was not enough to induce a global masculine representation of the dish. This seems to suggest that feminine connotation is more salient and diagnostic for representation of food than masculinity. A task for future studies is to delve more deeply into the exact mechanisms for this influence.

In addition, all of the investigated dimensions contributed to affect participants' eating intentions through food-gender association moderated by respondents' gender, even after controlling for their habitual consumption (in line with hypothesis 2). A Caprese salad, a small portion and an elegantly presented dish (in respect to the hamburger, the big portion and the roughly presented dish) tend to be considered "feminine food", and thus women expressed a more pronounced intention to eat it than men.

Therefore, our study presents three original results that might contribute to the literature on gender stereotypes about food. The first result is that, after disentangling food type and portion size, both of them contributed independently to induce a gender connotation. The second is that course elegance, in addition to neatness that was studied in previous research (Zellner et al., 2011), also contributed in conveying a feminine idea of a food. Third, we showed that all of the three investigated dimensions indirectly affected gender-congruent behavioral intention, particularly for women who were always found more willing to eat a food when they perceived it as more feminine (men presented the opposite pattern but it reached the statistical significance only for food type). Since we did not activate particular self-presentation motives, our findings highlight that gender-based stereotypes about food could also serve as a self-image construction (besides impression management) tool.

A limitation needs to be mentioned as it could open new avenues for research. A potential confounding factor remains in our experimental paradigm, because we selected from the pilot study a cooked (the hamburger) and an uncooked (the Caprese salad) dish to represent respectively the masculine and the feminine course. Actually, Rozin et al. (2012) underlined that there are good reasons to expect that cooked vs. uncooked food might elicit respectively feminine and masculine connotations, because women are still used to cook more than men. This might be the reason why we found that the hamburger did not receive very masculine polarized ratings. This aspect remains to be explored in future research.

Notwithstanding this limitation, we believe that our results have several important implications. First, they have theoretical implications concerning the understanding of the complex psychological dynamics acting in the process of food choice. They contribute to detect the set of implicit social norms the eaters face. In particular, our findings highlight that many contextual cues may give salience to gender identity (as well as other types of social identity, see Guidetti, Cavazza, \& Graziani, 2014) as a relevant motive underlying food selection.

From a practical point of view, the knowledge of such dynamics is of utmost importance for the prevention and the clinical management of health risk behaviors such as binge drinking, which is more frequently observed among men (e.g., Ricciardelli, Connor, Williams, \& Young, 2001) and eating disorders, which are more frequently observed among women (e.g., Hudson, Hiripi, Pope, \& Kessler, 2007). Paradoxically, despite women's healthier food habits, they usually show higher level of restrictive and emotional eating than men (e.g., Conner, Johnson, \& Grogan, 2004). In general, the differences between men's and women's diet cannot be explained only in terms of different physiological needs, but are also due to differences in cognition and motivations (Wardle et al., 2004). These different motivations arise from different social norms, for instance those driving women to diet from an increasingly younger 
Table 3

The conditional indirect effect of type of food, portion size and presentation on intention to eat the proposed food when food-gender association is the mediator and respondents' gender is the moderator

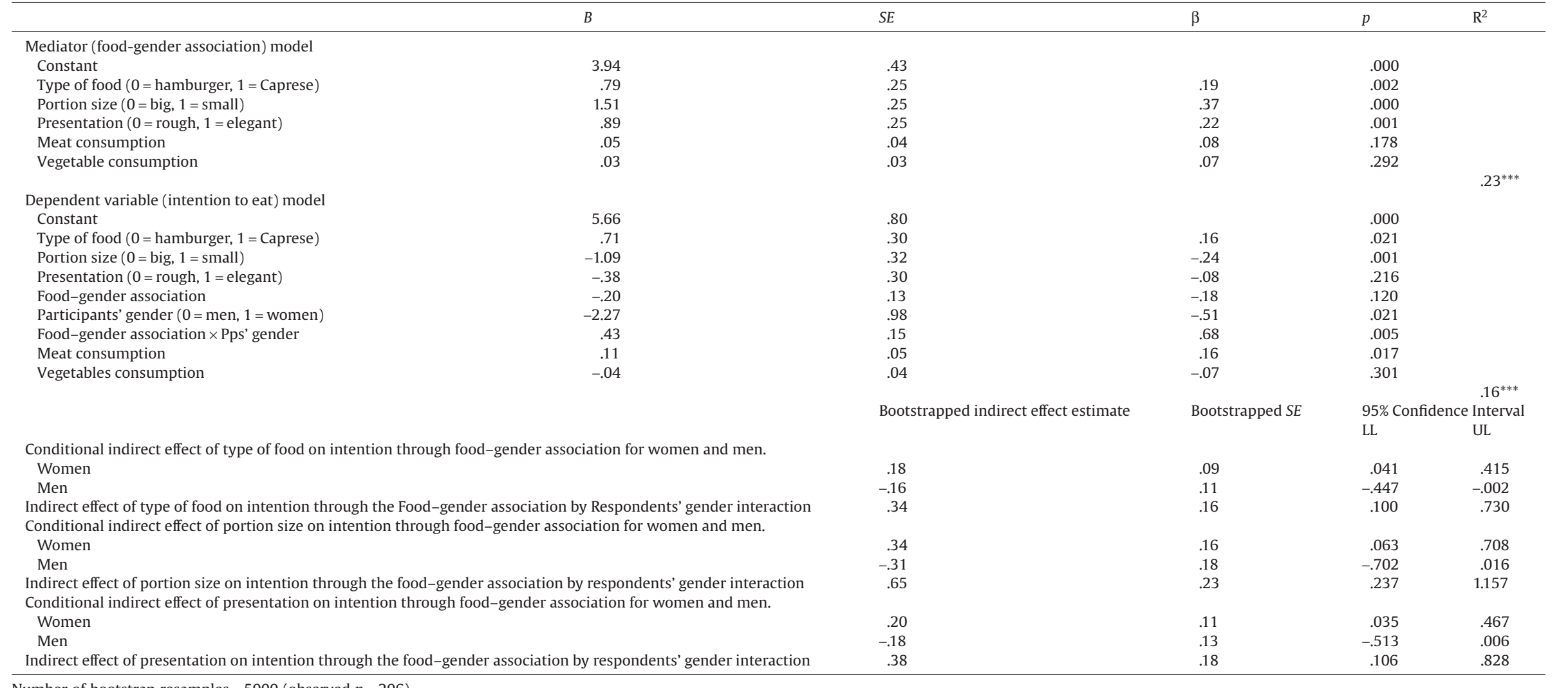

Number of bootstrap resamples $=5000$ (observed $n=206$ ).

**** $\mathrm{p}<.001$. 


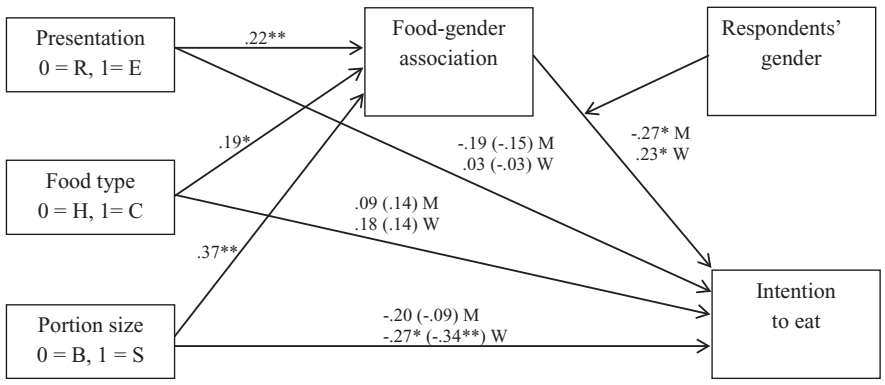

Fig. 1. Model of conditional indirect effects tested. Notes: $R=$ rough; $E=$ elegant; $\mathrm{H}=$ hamburger; $\mathrm{C}=$ Caprese salad; $\mathrm{B}=$ big; $\mathrm{S}=$ small; $\mathrm{M}=$ men; $\mathrm{W}=$ women. Coefficients are beta. ${ }^{*} p<.05{ }^{* *} p<.001$ (direct effect betas in parentheses).

age (Tanofsky-Kraff et al., 2004). This seems relevant in reference with portion size, which is, indeed, the most studied among the dimensions we investigated. Our experiment, however, indicates that women can count on other, more apparently innocuous, aspects of food in order to conform to social expectations and maintain their gender identity. As in case of other stereotypes, a line of research could be focused on the means to weaken such gender-based expectations able to affect energy intake or make people aware of their influence as an aspect of health education. Future research could explore whether portion size, type of food and presentation have the same impact on eating intention for people suffering with eating disorders, and how these stereotypes could be incorporated into intervention and prevention efforts. Our results may be of some interest also for food marketers and restaurateurs, who may take advantage of their awareness of the food stereotype aspects in designing their products.

\section{References}

Bourdieu, P. (1984). Distinction. A social critique of the judgment of taste. Cambridge, MA: Harvard University Press.

Chaiken, S., \& Pliner, P. (1987). Women, but not men, are what they eat. The effect of meal size and gender on perceived femininity and masculinity. Personality and Social Psychology Bulletin, 13, 166-176.

Chernev, A., \& Gal, D. (2010). Categorization effects in value judgments. Averaging bias in evaluating combinations of vices and virtues. Journal of Marketing Research, $47,738-747$.

Conner, M., Johnson, C., \& Grogan, S. (2004). Gender, sexuality, body image and eating behaviours. Journal of Health Psychology, 9, 505-515.

Counihan, C. M., \& Kaplan, S. L. (2004). Food and gender. Identity and power. London, UK: Routledge.

Fagerli, R. A., \& Wandel, M. (1999). Gender differences in opinions and practices with regard to a "healthy diet". Appetite, 32, 171-190.

Fiddes, N. (1991). Meat. A natural symbol. London: Routledge \& Kegan Paul.

Gal, D., \& Wilkie, J. (2010). Real men don't eat quiche. Regulation of gender-expressive choices by men. Social Psychological and Personality Science, 1(4), 291-301.

Guidetti, M., Cavazza, N., \& Graziani, A. R. (2014). Healthy at home, unhealthy outside: Food groups associated with family and friends and the potential impact on attitude and consumption. Journal of Social and Clinical Psychology, 33, 343-364.

Hayes, A. F. (2013). Introduction to mediation, moderation, and conditional process analysis: A regression-based approach. Guilford Press.

Helgeson, V. S. (1994). Prototypes and dimensions of masculinity and femininity. Sex Roles, 31, 653-682.
Herman, C. P., Roth, D. A., \& Polivy, J. (2003). Effects of the presence of others on food intake. A normative interpretation. Psychological Bulletin, 129, 873-886.

Hudson, J. I., Hiripi, E., Pope, H. G., Jr., \& Kessler, R. C. (2007). The prevalence and correlates of eating disorders in the National Comorbidity Survey Replication. Biological Psychiatry, 61, 348-358.

Kimura, A., Wada, Y., Asakawa, A., Masuda, T., Goto, S., Dan, I., et al. (2012). Dish influences implicit gender-based food stereotypes among young Japanese adults. Appetite, 58, 940-945.

Kimura, A., Wada, Y., Goto, S., Tsuzuki, D., Cai, D., Oka, T., et al. (2009). Implicit gender-based food stereotypes. Semantic priming experiments on young Japanese. Appetite, 52, 51-54.

Lupton, D. (1996). Food, the body and the self. London: Sage.

Martins, Y., Pliner, P., \& Lee, C. (2004). The effects of meal size and body size on individuals' impressions of males and females. Eating Behaviors, 5(2), 117-132.

Mooney, K. M., \& Lorenz, E. (1997). The effects of food and gender on interpersonal perceptions. Sex Roles, 36, 639-653.

Mori, D., Chaiken, S., \& Pliner, P. (1987). "Eating lightly" and the self-presentation of femininity. Journal of Personality and Social Psychology, 53, 693-702.

O’Doherty Jensen, K., \& Holm, L. (1999). Preferences, quantities and concerns. Socio-cultural perspectives on the gendered consumption of foods. European Journal of Clinical Nutrition, 53, 351-359.

Pliner, P., \& Chaiken, S. (1990). Eating, social motives, and self-presentation in women and men. Journal of Experimental Social Psychology, 26, 240-254.

Pringle, R., \& Collings, S. (1993). Women and butchery. Some cultural taboos. Australian Feminist Studies, 8, 29-45.

Ricciardelli, L. A., Connor, J. P., Williams, R. J., \& Young, R. M. (2001). Gender stereotypes and high risk drinking among young women and men. Drug and Alcohol Dependence, 61, 129-136.

Rolls, J. B., Fedoroff, C. I., \& Guthrie, F. J. (1991). Gender differences in eating behavior and body weight regulation. Health Psychology, 10, 133-142.

Rothgerber, H. (2013). Real men don't eat (vegetable) quiche. Masculinity and the justification of meat consumption. Psychology of Men E Masculinity, 14 363-375.

Rozin, P., Hormes, M. J., Faith, S. M., \& Wansink, B. (2012). Is meat male? A quantitative multimethod framework to establish metaphoric relationships. Journal of Consumer Research, 39, 629-643.

Sobal, J. (2005). Men, meat, and marriage. Models of masculinity. Food and Foodways, $13,135-158$.

Stein, R. I., \& Nemeroff, C. J. (1995). Moral overtones of food. Judgments of others based on what they eat. Personality and Social Psychology Bulletin, 21, 480490.

Tanofsky-Kraff, M., Yanovski, S. Z., Wilfley, D. E., Marmarosh, C., Morgan, C. M., \& Yanovski, J. A. (2004). Eating-disordered behaviors, body fat, and psychopathology in overweight and normal-weight children. Journal of Consulting and Clinical Psychology, 72, 53-61.

Vartanian, L. R., Herman, C. P., \& Polivy, J. (2007). Consumption stereotypes and impression management. How you are what you eat. Appetite, 48, 265-277.

Wadhera, D., \& Capaldi-Phillips, D. E. (2014). A review of visual cues associated with food on food acceptance and consumption. Eating Behaviors, 15, 132-143.

Wardle, J., Haase, A. M., Steptoe, A., Nillapun, M., Jonwutiwes, K., \& Bellisie, F. (2004) Gender differences in food choice. The contribution of health beliefs and dieting. Annals of Behavioral Medicine, 27, 107-116.

White, K., \& Dahl, D. W. (2006). To be or not be. The influence of dissociative reference groups on consumer preferences. Journal of Consumer Psychology, 16, 404-413.

Young, M. E., Mizzau, M., Mai, N. T., Sirisegaram, A., \& Wilson, M. (2009). Food for thought. What you eat depends on your sex and eating companions. Appetite, 53(2), 268-271.

Zellner, D. A., Loss, R. C., Zearfoss, J., \& Remolina, S. (2014). It tastes as good as it looks! The effect of food presentation on liking for the flavor of food. Appetite, $77,31-35$.

Zellner, D. A., Siemers, E., Teran, V., Conroy, R., Lankford, M., Agrafiotis, A., et al. (2011). Neatness counts. How plating affects liking for the taste of food. Appetite, 57, 642-648.

\section{Appendix: Supplementary material}

Supplementary data to this article can be found online at doi:10.1016/j.appet.2015.04.068. 